\title{
Expression Patterns of $\alpha$-Synuclein in Human Hematopoietic Cells and in Drosophila at Different Developmental Stages
}

\author{
Eui Cheol Shin, Seong Eun Cho, Dong-Kee Lee ${ }^{1}$, Man-Wook Hur ${ }^{1}$, Seung R. Paik ${ }^{2}$, Jeon Han Park, and \\ Jongsun Kim* \\ Department of Microbiology, Yonsei University College of Medicine, Seoul 120-752, Korea; \\ ${ }^{1}$ Department of Biochemistry and Molecular Biology, Yonsei University College of Medicine, Seoul 120-752, Korea; \\ ${ }^{2}$ Department of Biochemistry, Inha University College of Medicine, Incheon 402-751, Korea.
}

(Received on October 5, 1999)

$\alpha$-Synuclein, a presynaptic protein of the central nervous system, has been implicated in the synaptic events such as neuronal plasticity during development and learning, and neuronal degeneration under pathological conditions. As an effort to understand the biological function of $\alpha$-synuclein, we examined the expression patterns of $\alpha$-synuclein in various human hematopoietic cells, and in Drosophila at different developmental stages. The $\alpha$-synuclein was ubiquitously expressed in all the tested hematopoietic cells including $\mathrm{T}$ cells, $\mathrm{B}$ cells, NK cells, and monocytes, as well as in the lymphoma cell lines, Jurkat and K562. A potential $\alpha$-synuclein homologue was also expressed in Drosophila, and its expression appeared to be temporally and spatially regulated during development. Our data suggest that $\alpha$-synuclein may function in invertebrates as well as in vertebrates and its function may not be restricted to the neuron.

Keywords: Development; Gene Expression; NACP; Neurodegenerative Disease; Synuclein.

\section{Introduction}

$\alpha$-Synuclein, also known as the precursor protein of the non-A $\beta$ component of Alzheimer's disease amyloid (NACP), is a presynaptic protein of unknown function composed of 140 amino acid residues (Iwai et al., 1995; Jakes et al., 1994; Ueda et al., 1993). Synuclein was first identified in electric fish (Maroteaux et al., 1988), and subsequently identified in rat (Maroteaux and Scheller, 1991; Shibayama-Imazu et al., 1993; Tobe et al., 1992), bovine (Nakajo et al., 1990; 1993), human (Jakes et al., 1994; Ueda et al., 1993), and canary bird (George et al., 1995). The synuclein protein has a sequence that has been highly conserved among birds, fish, and mammals. $\alpha$ Synuclein is expressed primarily in the nervous system, where it is concentrated in presynaptic nerve terminals (Irizarry et al., 1996; Iwai et al., 1995; Jakes et al., 1994; Ueda et al., 1993). However, it is also expressed in other tissues including the heart, skeletal muscle, pancreas, and placenta, though less abundantly than in the brain (Jakes et al., 1994; Ueda et al., 1993; 1994). The physiological function of $\alpha$-synuclein is not clear, but the predominant localization of the protein at presynaptic nerve terminals (Irizarry et al., 1996; Iwai et al., 1995; Jakes et al., 1994; Ueda et al., 1993) suggests that it may play a critical role in synaptic events, such as neuronal plasticity during development (Withers et al., 1997) and learning (George et al., 1995), and degeneration of nerve terminals under pathological conditions in Alzheimer's disease (Brooks et al., 1994; Ueda et al., 1993) and Parkinson's disease (Polymeropoulos et al., 1997; Spillantini et al., 1998).

To better understand the biological function of $\alpha$ synuclein, we examined the expression patterns of $\alpha$ synuclein in various human hematopoietic cells, and in an invertebrate system, Drosophila, at different developmental stages. We demonstrate here that $\alpha$ synuclein is ubiquitously expressed in hematopoietic cells including T cells, B cells, NK cells, and monocytes, as well as in the lymphoma cell lines, Jurkat and K562. We also show that a potential $\alpha$-synuclein homologue is expressed in Drosophila, and the expression of the protein appears to be differentially regulated during development.

Abbreviations: NACP, non-A $\beta$ component of Alzheimer's disease; NK cells, natural killer cells; PBMC, peripheral blood mononuclear cell.
* To whom correspondence should be addressed.

Tel: 82-2-361-5277; Fax: 82-2-392-7088

E-mail: jkim63@yumc.yonsei.ac.kr 


\section{Materials and Methods}

Separation of $T$ cells, $B$ cells, NK cells, and monocytes from PBMCs Peripheral blood mononuclear cells (PBMCs) were purified by Ficoll-Hypaque (Pharmacia, Uppsala, Sweden) density gradient centrifugation from $5 \mathrm{ml}$ of heparinized peripheral blood donated by a healthy volunteer. T cells, B cells, NK cells, and monocytes were isolated from PBMCs by immunomagnetic beads (Dynal, Great Neck, NY). Briefly, PBMCs were washed and resuspended in RPMI 1640 supplemented with $1 \%$ fetal bovine serum at a concentration of 2-3 $\times 10^{6}$ cells $/ \mathrm{ml}$. Positive selection for monocytes was performed by incubating PBMCs with anti-CD14 immunomagnetic beads for $30 \mathrm{~min}$ at $4^{\circ} \mathrm{C}$ on a rotating shaker. The unbound cells were then incubated with anti-CD3 immunomagnetic beads for $\mathrm{T}$ cell separation. Subsequently, B cells were separated from the unbound cells with anti-CD19 immunomagnetic beads. In the remaining cells, characterization of the surface marker was performed by flow cytometry analysis. More than $90 \%$ of these cells were $\mathrm{CD}^{-} \mathrm{CD} 16^{+}$or $\mathrm{CD}^{-}{ }^{-} \mathrm{CD} 56^{+}$, and these cells were considered as NK cells.

RT-PCR analysis Total RNA was isolated from purified hematopoietic cells by acid guanidium isothiocyanate-phenolchloroform extraction. The first strand cDNA was synthesized by using 1-5 $\mu \mathrm{g}$ of RNA, 0.1 O.D. unit of random hexamer (Pharmacia, Uppsala, Sweden), and 600 units of MLV reverse transcriptase (Gibco BRL, Gaithersburg, MD) in a total volume of $100 \mu$. The reaction mixture was incubated for $1 \mathrm{~h}$ at $42^{\circ} \mathrm{C}$ and used for PCR. The N-terminal part of $\alpha$-synuclein (307 bp) was amplified by PCR using $5 \mu \mathrm{l}$ of cDNA and Taq DNA polymerase with the primer set, $\mathrm{N} 1$ and $\mathrm{C} 1$, and the C-terminal part of $\alpha$ synuclein (179 bp) was amplified with the primer set, N2 and C2 (Fig. 1A). The complete protein-coding region of $\alpha$-synuclein (445 bp) was also amplified by PCR using N1 and C2 oligonucleotide primers. Similar primer sets were designed and used for the amplification of $\beta$-synuclein cDNA, and the sequences of the primers were GCCAGGATGGACGTGTTCATG ( $\beta N 1)$, GGCTGCTGCGATGTTCCCTGC ( $\beta C 1)$, GCCTCACATCTGGGAGGAGCT ( $\beta$ N2), and CCCCTACGCCTCTGGCTCATA $(\beta C 2)$, respectively.

Purification and antibody production of $\alpha$-synuclein $\alpha$ Synuclein was overexpressed in E. coli and the recombinant protein was purified as previously described (Jakes et al., 1994; Kim, 1997; Paik et al., 1997). Polyclonal antibody was raised against the purified recombinant protein. Briefly, $\alpha$-synuclein $(500 \mu \mathrm{g})$ was mixed at a 1:1 ratio with Freund's complete adjuvant (Sigma, Saint Louis, MO) and used to immunize a white Dutch rabbit. A booster injection was given three weeks after the primary immunization using $250 \mu \mathrm{g}$ of protein mixed at a 1:1 ratio with Freund's incomplete adjuvant (Sigma). Another booster injection was given after an additional three weeks, and the animal was bled two weeks later.

Western blot analysis Cell lysates were resolved on 12\% SDS acrylamide gels, and the proteins were transferred onto PVDF membranes. Western blot analysis was performed with the polyclonal anti- $\alpha$-synuclein antibody. The blots were developed using secondary horseradish peroxidase-conjugated sheep anti- rabbit IgG antibody (Amersham, Buckinghamshire, England) and ECL substrate (Amersham).

Temporal and spatial expression patterns of Drosophila $\alpha$ synuclein The embryos fixed with formaldehyde/glutaraldehyde were rehydrated with BBT (PBS containing $0.1 \%$ Tween-20, $0.1 \%$ BSA) and blocked with BBS (BBT containing $2 \%$ serum) for $40 \mathrm{~min}$. Then they were washed with BBT and incubated with purified anti- $\alpha$-synuclein antibody overnight at $4^{\circ} \mathrm{C}$. The embryos were again washed with BBT and blocked with BBS. They were incubated with biotinylated secondary antibody $(\mathrm{ABC}$ kit, Vector Laboratories, $\mathrm{CA}$ ) for $2 \mathrm{~h}$ at room temperature, then washed with PBT (PBS containing $0.1 \%$ Tween-20). They were then incubated with the A + B mix (Vector Laboratory) for $1 \mathrm{~h}$ at room temperature, and washed with PBT. Finally, the embryos were stained by incubating in peroxidase substrate solution containing DAB (DAB $0.5 \mathrm{mg} / \mathrm{ml}, 0.015 \% \mathrm{H}_{2} \mathrm{O}_{2}$ in PBT) and mounted with Permount (Fisher, PA).

\section{Results and Discussion}

To investigate the expression of $\alpha$-synuclein and $\beta$ synuclein in hematopoietic cells, RT-PCR was carried out using cDNAs obtained from pheripheral blood mononuclear cells (PBMCs). Two pairs of oligonucleotide primers were designed to amplify the $\mathrm{N}$ - and C-terminal parts of $\alpha$-synuclein (Fig. 1A). RT-PCR analysis demonstrated that significant amounts of $\alpha$-synuclein mRNA was present in PBMCs. Similar RT-PCR analysis was carried out for $\beta$-synuclein with $\beta$-synuclein-specific oligonucleotide primers, but the amplification of $\beta$ synuclein cDNA was not observed (Fig. 1B), suggesting that the $\beta$-synuclein was not expressed in PBMCs. We next investigated the cell type expression of $\alpha$-synuclein in hematopoietic cells. PBMCs were further fractionated into $\mathrm{T}$ cells, B cells, NK cells, and monocytes, and RT-PCR analysis was performed using cDNAs obtained from these cells. Figure 2 shows that $\alpha$-synuclein mRNA is ubiquitously expressed in all the tested hematopoietic cells including $\mathrm{T}$ cells, B cells, NK cells, and monocytes. However, $\beta$-synuclein was not detected in any of the hematopoietic cells by RT-PCR analysis (data not shown). These results suggest that the expressions of $\alpha$-synuclein and $\beta$-synuclein are differentially regulated in human tissues.

We also investigated whether $\alpha$-synuclein protein was expressed in hematopoietic cells. Western blot analysis with polyclonal antibody against the recombinant $\alpha$ synuclein revealed that two major protein bands ( $37 \mathrm{kDa}$ and $19 \mathrm{kDa}$ ) were strongly reactive to the antibody (Fig. 3A). The $37 \mathrm{kDa}$ protein is an unidentified protein which is cross-reactive against anti- $\alpha$-synuclein antibodies (Hashimoto et al., 1997; Ueda et al., 1993). Bacterially expressed $\alpha$-synuclein protein almost co-migrated with the $19 \mathrm{kDa}$ protein. The slight difference in mobility may indicate that $\alpha$-synuclein is posttranslationally modified in 
A

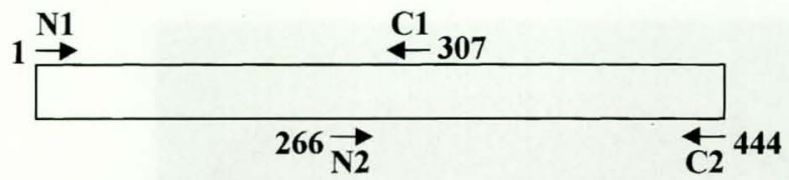

N1: AATTCCATTAGCCATGGATGTA

C1 : TGCTCCCTCCACTGTCTTCTG

N2: ACGgGTGTGACAGCAGTAGCC

C2 : AGATATTTCTTAGGCTTCAGG
B

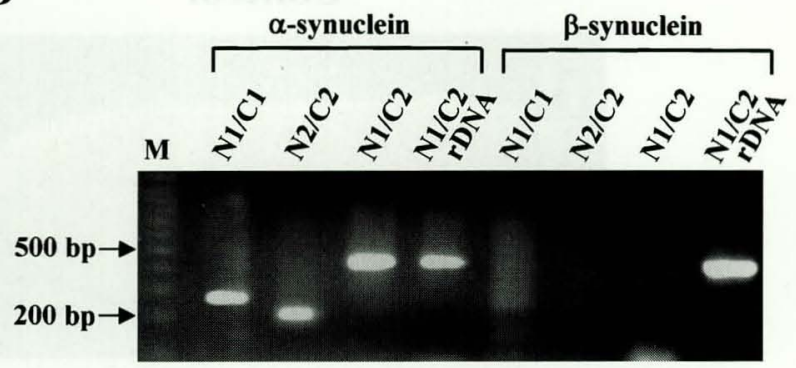

Fig. 1. $\alpha$-Synuclein primer sets and RT-PCR analysis. A. $\alpha$-synuclein primer sets for RT-PCR. Primer set N1/C1 amplifies the N-terminal part (307 bp), N2/C2 amplifies the C-terminal part (179 bp), and N1/C2 amplifies whole cDNA of $\alpha$-synuclein (445 bp). Similar primer sets were used for $\beta$-synuclein as described in Materials and Methods. B. Expression of $\alpha$ - and $\beta$-synuclein in PBMCs. RT-PCR analysis shows that $\alpha$-synuclein is expressed in PBMCs, but $\beta$-synuclein is not. Recombinant DNAs of $\alpha$ - and $\beta$-synuclein were used as positive controls.

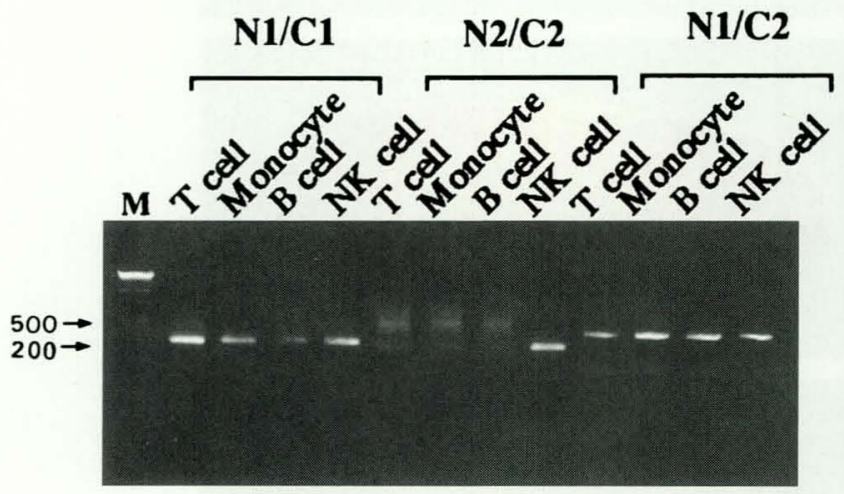

Fig. 2. Ubiquitous expression of $\alpha$-synuclein in immune cells. RT-PCR analysis shows that $\alpha$-synuclein is expressed in T cells, B cells, NK cells, and monocytes. As described in Fig. 1, primer set $\mathrm{N} 1 / \mathrm{C} 1$ amplifies the $\mathrm{N}$-terminal part, N2/C2 amplifies the $\mathrm{C}$ terminal part, and N1/C2 amplifies whole cDNA of synuclein.
PBMCs, as has been observed in brain cells (Jakes et al., 1994). In addition, previous works have shown that $\alpha$ synuclein runs slightly faster than $\beta$-synuclein on SDSPAGE (Jakes et al., 1994). Taken together, these results indicate that the $19 \mathrm{kDa}$ protein is $\alpha$-synuclein. In some PBMCs, the alternatively spliced form of $\alpha$-synuclein (NACP112 composed of 112 amino acids, $14 \mathrm{kDa}$ ) was also detected (Fig. 3A, PBMC4). The $\alpha$-synuclein was also detected in two leukemia cell lines, Jurkat and K562 (Fig. 3B). Expression of $\alpha$-synuclein in K562 cells has previously been described (Hashimoto et al., 1997).

Using the anti- $\alpha$-synuclein antibody, we found that a 19 $\mathrm{kDa}$ protein is also present in adult bodies and embryos of Drosophila (Fig. 3C). Interestingly, the band intensity of the $19 \mathrm{kDa}$ protein was weaker in embryos, suggesting that the expression of the protein is developmentally regulated. This was further supported by the fact that the potential

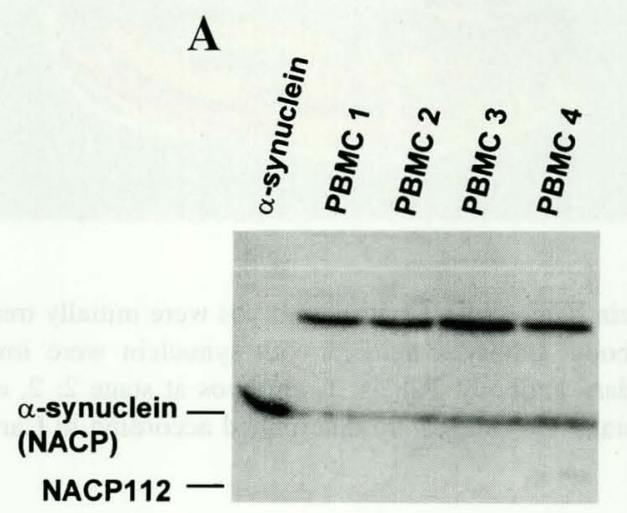

B

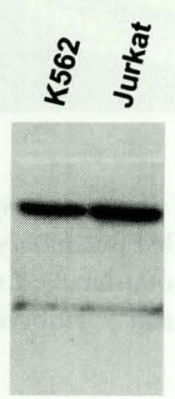

C

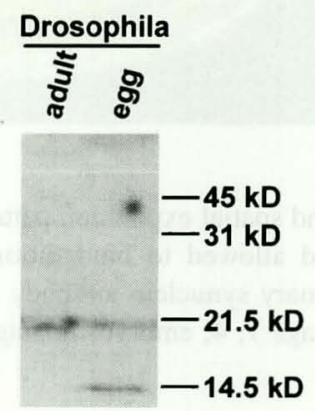

Fig. 3. Western blot analysis of $\alpha$-synuclein. About $200 \mu \mathrm{g}$ of total cell proteins were loaded into each lane, and $0.1 \mu \mathrm{g}$ of recombinant $\alpha$-synuclein was used as a positive control. A. Western blot analysis indicates that $\alpha$-synuclein (19 kDa) is expressed in PBMCs. The $37 \mathrm{kDa}$ band represents a unidentified protein which is cross-reactive against anti- $\alpha$-synuclein antibodies (Hashimoto et al., 1997 ; Ueda et al., 1993). B. Expression of $\alpha$-synuclein in the lymphoma cell lines, Jurkat and K562. C. A potential $\alpha$-synuclein homologue (19 kDa) is also expressed in Drosophila. The $14 \mathrm{kDa}$ band in (A) and (C) may represent an alternative splicing form of $\alpha$-synuclein (NACP112) composed of the N-terminal 112 amino acids. 


\section{Control} Synuclein
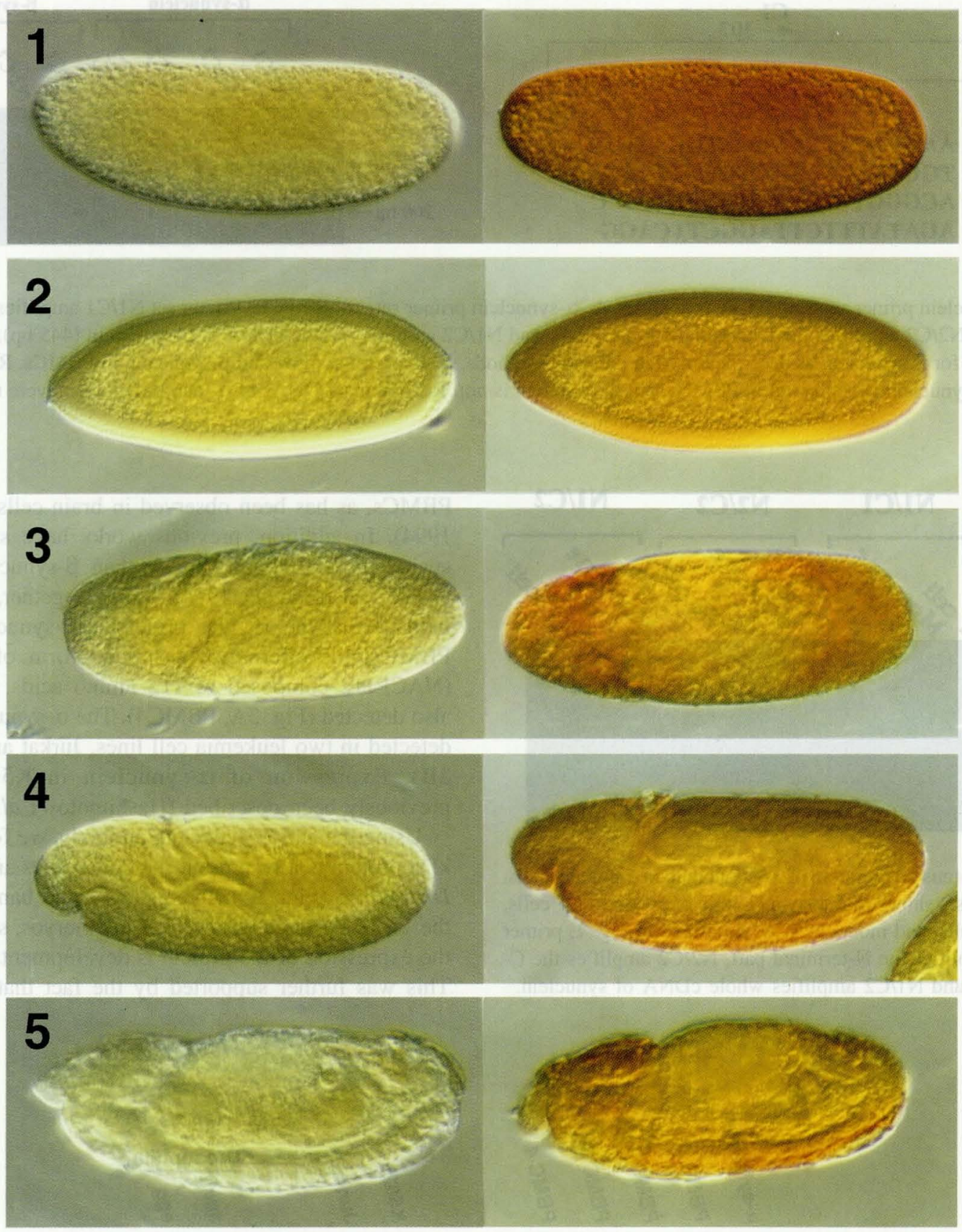

Fig. 4. Temporal and spatial expression patterns of Drosophila synuclein homologue. Control embryos were initially treated with bovine serum albumin and allowed to bind biotin-labelled secondary antibody. Embryos marked with synuclein were immunostained by treatment with primary synuclein antibody and biotin-labelled secondary antibody. Panels: 1, embryos at stage 2 ; 2, embryos at stage 5; 3, embryos at stage 7; 4, embryos at stage 10; and 5, embryos at stage 13. (Stages are determined according to Campos-Ortega and Hartenstein, 1985). 
NACP112 homologue (an alternatively spliced form of $\alpha$ synuclein, $14 \mathrm{kDa}$ ) was only detected in Drosophila embryos, but not in adult bodies (Fig. 3C). It is intriguing to note that NACP112 is only found in fetal tissues, while the full-length $\alpha$-synuclein was found in all human tissues examined (Ueda et al., 1994). Similar phenomena have been observed in a rat and canary bird. The expression of a synuclein homologue in a rat, phosphoneuroprotein 14 (PNP14), increased during the first month of the neonatal period (Shibayama-Imazu et al., 1993), and the canary homologue, synelfin, was locally upregulated in the song control circuit during a critical period for song learning (George et al., 1995). In addition, Hashimoto et al. (1997) reported that the expression of $\alpha$-synuclein in a megacaryocyte-platelet system is differentially regulated during megacaryocyte differentiation.

To verify the possibility that the expression of $\alpha$ synuclein homologue is differentially regulated during development, we investigated the temporal and spatial expression patterns of $\alpha$-synuclein homologue in Drosophila embryos at different developmental stages. The embryos were collected for $15 \mathrm{~h}$ and immunostained with affinity-purified anti- $\alpha$-synuclein antibody. Immunostaining of the embryos showed that the synuclein was expressed across the whole embryo in early stage 2 embryos (Fig. 4, panel 1) and showed the highest level of expression during development. At stage 5, synuclein was expressed evenly across the embryo but at somewhat lower level (Fig. 4, panel 2). At stage 7, synuclein was expressed higher at the anterior (cephalic furrow) and posterior $30 \%$ region than in other parts of the embryo (Fig. 4, panel 3). At stage 10, the procephalon and dorsal regions showed a higher expression of synuclein particularly at a region around clypeolabrum (Fig. 4, panel 4). At stage 13, synuclein showed higher expression in the procephalon and ventral nerve cord regions (Fig. 4, panel 5). In summary, the protein was expressed ubiquitously and higher at early stages but the expression level decreased at later stages. As well, the protein was expressed slightly higher at the central nerve system (brain and nerve cord) in the later stages, which is in line with its function in the central nerve system.

In this report, we showed that $\alpha$-synuclein is expressed in hematopoietic cells including T cells, B cells, NK cells, and monocytes, as well as in the lymphoma cell lines, Jurkat and K562, suggesting that $\alpha$-synuclein is ubiquitously expressed in hematopoietic cells. The ubiquitous expression of $\alpha$-synuclein in hematopoietic cells could make it possible to design a diagnostic method for neurodegenerative diseases associated with the protein, and could make it convenient for detecting a genetic change in this protein. For example, the Ala to Ser change in familial Parkinsonism (Polymeropoulos et al., 1997) or abnormally processed forms of $\alpha$-synuclein protein can be easily detected by DNA sequence analysis of RT-PCR products or immunostaining of proteins obtained from a blood sample. Further, we showed that the $\alpha$-synuclein homologue is expressed in Drosophila, and that the expression of the protein appears to be temporally and spatially regulated during development. The protein was ubiquitously expressed in embryos at early stages of development, while it was highly expressed in brain and nerve cord of embryos at later stages. Taken together, our data suggest that $\alpha$-synuclein may function in invertebrates, as well as in vertebrates, and that the function may not be restricted to the neuron. Particularly, the presence of the $\alpha$-synuclein homologue in Drosophila will provide better opportunities for investigating the biological function of the protein through transgenic or knock-out studies.

Acknowledgments We thank Dr. R. Jakes for the recombinant DNA of $\alpha$-synuclein, Bob Ross for critical reading of the manuscript, and H. I. Cho for technical assistance. This work was supported by a grant from the KOSEF (1999-2-209014-5).

\section{References}

Brookes, A. J. and Clair, D. S. (1994) Synuclein proteins and Alzheimer's disease. Trends in Neurosci. 17, 404-405.

Campos-Ortega, J. A. and Hartenstein V. (1985) The Embryonic Development of Drosophila melanogaster, Springer Verlag, Berlin.

George, J. M., Jin, H., Woods, W. S., and Clayton, D. F. (1995) Characterization of a novel protein regulated during the critical period for song learning in the Zebra finch. Neuron $\mathbf{1 5}$, 361-372.

Hashimoto, M., Yoshimoto, M., Sisk, A., Hsu, L. J., Sundsmo, M., Kittel, A., Saitoh, T., Miller, A., and Masliah, E. (1997) NACP, a synaptic protein involved in Alzheimer's disease, is differentially regulated during Megakaryocyte differentiation. Biochem. Biophys. Res. Commun. 237, 611-616.

Irizarry, M. C., Kim, T. W., McNamara, M., Tanzi, R. E., George, J. M., Clayton, D. F., and Hyman, B. T. (1996) Characterization of the precursor protein of the non- $A \beta$ component of senile plaques (NACP) in the human central nervous system. J. Neuropathol. Exp. Neurol. 55, 889-895.

Iwai, A., Masliah, E., Yoshimoto, M., Ge, N., Flanagan, L., Rohan del Silva, A., and Saitoh, T. (1995) The precursor protein of non-A $\beta$ component of Alzheimer's disease amyloid is a presynaptic protein of the central nervous system. Neuron 14, 467-475.

Jakes, R., Spillantini, M. G., and Goedert, M. (1994) Identification of two distinct synucleins from human brain. FEBS Lett. 345, 27-32.

Kim, J. (1997) Evidence that the precursor protein of non-A $\beta$ component of Alzheimer's disease amyloid (NACP) has an extended structure primarily composed of random-coil. $\mathrm{Mol}$. Cells 7, 78-83.

Maroteaux L. and Scheller, R. H. (1991) The rat brain synucleins; family of proteins transiently associated with neuronal membranes. Mol. Brain Res. 11, 335-343.

Maroteaux, L., Campanelli, J. T., and Scheller, R. H. (1988) Synuclein: a neuron-specific protein localized to the nucleus and presynaptic nerve terminal. J. Neurosci. 8, 2804-2815. 
Nakajo, S., Omato, K., Aiuchi, T., Shibayama, T., Okahashi, I., Ochiai, H., Nakai, Y., Nakaya, K., and Nakamura, Y. (1990) Purification and characterization of a novel brain-specific 14 kDa protein. J. Neurochem. 55, 2031-2038.

Nakajo, S., Tsukada, K., Omata, K., Nakamura, Y., and Nakaya, $\mathrm{K}$. (1993) A new brain-specific $14 \mathrm{kDa}$ protein is a phosphoprotein. Its complete amino acid sequence and evidence for phosphorylation. Eur. J. Biochem. 217, 10571063.

Paik, S. R., Lee, J.-H., Kim, D.-H., Chang, C.-S., and Kim, J. (1997) Aluminum-induced structural alterations of the precursor protein of non-A $\beta$ component of Alzheimer's disease amyloid. Arch. Biochem. Biophys. 344, 325-334.

Polymeropoulos, M. H., Lavedan, C., Leroy, E., Ide, S. E., Dehejia, A., Dutra, A., Pike, B., Root, H., Rubenstein, J., Boyer, R., Stenroos, E. S., Chandrasekharappa, S., Athanassiadou, A., Papapetropoulos, T., Johnson, W. G., Lazzarini, A. M., Duvoisin, R. C., Di Iorio, G., Golbe, L. I., and Nussbaum, R. L. (1997) Mutation in the $\alpha$-synuclein gene identified in families with Parkinson's disease. Science 276, 2045-2047.

Shibayama-Imazu, T., Okahashi, I., Omata, K., Nakajo, S., Ochiai, H., Nakai, Y., Hama, T., Nakamura, Y., and Nakaya, K.
(1993) Cell and tissue distribution and developmental change of neuron specific $14 \mathrm{kDa}$ protein (phosphoneuroprotein 14). Brain Res. 622, 17-25.

Spillantini, M. G., Crowther, R. A., Jakes, R., and Hasegawa, M. (1998) $\alpha$-Synuclein in filamentous inclusions of Lewy bodies from Parkinson's disease and dementia with Lewy bodies. Proc. Natl. Acad. Sci. USA 95, 6469-6473.

Tobe, T., Nakajo, S., Tanaka, A., Mitoya, A., Omata, K., Nakaya, K., Tomita, M., and Nakamura, Y. (1992) Cloning and characterization of the cDNA encoding a novel brain specific 14-kDa protein. J. Neurochem. 59, 1624-1629.

Ueda, K., Fukushima, H., Masliah, E., Xia, Y., Iwai, A., Yoshimoto, M., Otero, D. A. C., Kondo, J., Ihara, Y., and Saitoh, T. (1993) Molecular cloning of cDNA encoding an unrecognized component of amyloid in Alzheimer disease. Proc. Natl. Acad. Sci. USA 90, 11282-11286.

Ueda, K., Saitoh, T., and Mori, H. (1994) Tissue-dependent alternative splicing of mRNA for NACP, the precursor of non$\mathrm{Ab}$ component of Alzheimer's disease amyloid. Biochem. Biophys. Res. Commun. 205, 1366-1372.

Withers, G. S., George, J. M., Banker, G. A., and Clayton, D. F. (1997) Delayed localization of synelfin (synuclein/NACP) to presynaptic terminals in cultured rat hippocampal neurons. Dev. Brain Res. 99, 87-94. 